\section{Change at the Karolinska}

Along with the Mayo Clinic, the Karolinska Institute in Stockholm is arguably the world's best known freestanding medical school. Founded early in the nineteenth century when defects in the Swedish Army's arrangements for treating wounded soldiers became apparent, the school now takes in 280 would-be physicians every year, together with more than a hundred potential orthodontists and a larger number of physiotherapists. Yet, as things have turned out, research and graduate training have become dominant, accounting for 80 per cent of the institute's budget. In total, there are 1,500 research students, not all of whom are physicians as well, and a similar number of full-time scientific staff.

The concept of a freestanding medical school is unusual. At Aarhus, Denmark, the university is the product of the recognition that a medical school cannot easily stand alone. But Stockholm is different, with two well-established universities and thus no shortage of expertise for teaching nonmedical subjects to would-be doctors.

The institute proper has nevertheless grown over the decades haphazardly. Only in the past few years has the administration taken a rationalizing axe to the proliferation of departments more than a hundred of them - reducing the number now to fewer than three dozen. The principle had been that an able person recruited to the institute would be established in his own department, often physically separate from existing buildings. A consequence of the rationalization now under way will be the need to house larger groups of people in larger buildings, whence the scemingly endless construction work visible on the site of the northern campus $8 \mathrm{~km}$ from central Stockholm.

As part of the reorganization it is also agreed that most scientists should now compete for research funds with other applicants to the research councils from universities and elsewhere. The system has not been in place long enough for there to be a groundswell of discontent from disappointed applicants frozen out of research prematurely in their opinion. Despite the growing strength of the life sciences at other institutions in Sweden, it is likely that the Karolinska will be able to get more than its arithmetical share of the funds available.

Prestige helps. At the beginning of the century, the Karolinska Institute accepted what many thought to be the poisoned chalice of making annual nominations to the Nobel Foundation of prizewinners in physiology and medicine. In the event, the duty has proved more interesting than onerous. Indeed, because the institute is equipped by the Nobel Foundation to keep up with current developments in physiology and medicine throughout the world, its function as a listening post for Nobel prizes seems also to be a useful adjunct to the administrative task of plotting a strategy at the very least, it keeps senior people's ears close to the ground.

The Nobel connection also lends prestige, which is one reason why the northern Karolinska campus has an uneasy relationship with the new campus at Huddinge, on the other side of Stockholm, where there is a brand-new hospital and perhaps more striking, a Centre for Biotechnology.

Biotechnology has no obvious place in a medical school as distinct from, say, a pharmaceutical manufacturing plant. The biotechnology centre at Huddinge owes its existence to Professor Jan-Ake Gustafsson and to the Stockholm City Council, which has provided support for the centre since its foundation in 1985.

In its way, the centre is meant as a piece of Swedish social engineering. The southern suburbs of Stockholm are traditionally relatively poor - they are where newly arrived immigrants tend to live, for example. Part of the city council's objective has been to improve job prospects for these people and to enliven a part of the city previously empty of work spaces.

The result, so far not complete, is modestly spectacular. The Centre for Biotechnology now lives in what is called the Novum Building, a glass building with strips of pastel-coloured plastic marking joins between services and with preparation rooms as spotless as operating theatres. The staff, while no longer growing quickly, works at a series of fundamental problems relevant to more applied ventures in biotechnology. One project, for example, is to use the Semliki Forest virus as a means of generating proteins of predetermined structure as well as a vector for transfecting naive cells with unspecified genes.

On the face of things it seems unlikely that the Karolinska's reputation will in any way be tarnished. Whether the basic research will spawn the sheaf of biotechnology companies that people originally hoped for is a still untested proposition, even though the city council has set aside a large tract of land still further south than the Novum building.

Gustafsson says that he nevertheless finds the interaction with the city council both necessary and salutary. It is necessary to keep the council happy with the research programme under way but at the same time it is valuable to learn from elected politicians of the enthusiasm their taxpayers hold for what remains a somewhat daring venture. In all the circumstances, the Centre for Biotechnology seems set for at least as many years ahead as the seven it has enjoyed so far. But prudently, its Novum building is apparently leasehold, not freehold.

\title{
Following ancestral footsteps
}

Michael Sohlman, the new director of the Nobel Foundation, appointed last May, has hired a steel band from Copenhagen to play at the banquet after this month's Nobel prize ceremonies. The band is in honour of Derek Walcott, the Caribbean poet who is this year's winner of the literature award. Sohlman plans no other innovations this year.

Sohlman's appointment to the Nobel Foundation is nevertheless of great interest. His grandfather worked for Alfred Nobel as an engineer in Paris at the turn of the century. On Nobel's death, he took charge of the operation of collecting together Nobel's assets in France and of transporting them to Sweden. The operation entailed the purchase of a Fiat motor car and two pistols to keep potential robbers at bay. The younger Sohlman says that this hazardous operation was nevertheless entirely legal. By his account, French law at the time specified that a person's domicile was the place at which he kept his horses which, in Nobel's case, was Sweden, not Paris.
The younger Sohlman, who describes himself as a "simple Treasury man" says that he sees no need for radical changes at the foundation, which is in any case

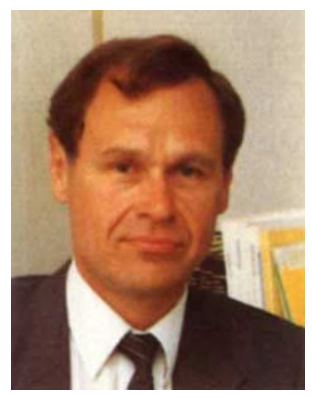

Nobel dlrector Sohlman: sees no need for radical changes.

tightly circumscribed by Nobel's will. But he regards the relationship between the foundation and the nominating organizations specified in Nobel's will as crucial to the success of the operation, noting that the foundation itself is not able to make accurate scientific judgements but that it can monitor the way in which the nominating bodies go about their task. 